\title{
BEHAVIOUR OF BI-ADHESIVE IN DOUBLE-STRAP JOINT WITH EMBEDDED PATCH SUBJECTED TO BENDING*
}

\author{
Şemsettin Temiz, Hamit Adin \\ Department of Mechanical Engineering, Faculty of Engineering, \\ Batman University, 72060 Batman, Turkey, \\ e-mails: semsettin.temiz@batman.edu.tr, hamit.adin@batman.edu.tr \\ ISMAIL YASIN SÜLÜ \\ Department of Mechanical Engineering, Faculty of Engineering, \\ Inonu University, 44280 Malatya, Turkey \\ e-mail: ismail.sulu@inonu.edu.tr
}

[Received 20 April 2015. Accepted 15 June 2015]

\begin{abstract}
In this study, behaviour of bi-adhesive used in the repair of damaged parts was analyzed, using the finite element method. In a double-strap joint with an embedded patch, patch is embedded into the adherents for structural requirements. In addition, to increase the strength of the joint, two adhesives are used to bond the adherents. This approach reduces stress concentration at the overlap ends, increases the load capacity and delays the failure. These effects give rise to higher joint strength. For this purpose, a stiff adhesive, FM73 produced by Cytec Fiberite, was applied in the middle portion of the overlap, while a softer adhesive, SBT9244 from 3M, was applied towards the edges, prone to stress concentrations. Non-linear finite element analyses were carried out to predict the failure loads, to assist with the geometric design and to identify effective ratios of sizes to maximize joint strength.

KEY WORDs: Bi-adhesive, double-strap joints, finite element analysis, mechanical properties, stress analysis, failure loads.
\end{abstract}

\section{Introduction}

The classical double-strap adhesive joint is preferred in both bonding and repair of damaged parts, particularly in the aircraft and automotive industries [1-5]. In the classical double-strap joint, patches form protrusions at the

\footnotetext{
${ }^{*}$ Corresponding author e-mail: hamit.adin@batman.edu.tr
} 
outer surface, which limits backward, forward and circular mobility of the parts only in narrow areas. Double-strap joint with embedded patch eliminates these protrusions, therefore, the movement restrictions are removed and smoother surfaces are obtained. In addition, coating and painting operations are easier over the obtained smoother surfaces, and a better view is obtained in terms of construction and aesthetic [6].

The reduction of transverse shear and normal stress concentrations along the edges of adhesive bondlines is important, in order to prevent premature failure of the bonded joint. Due to differential straining in the substrates, adhesively-bonded joints inevitably experience stress concentrations, especially in the adhesive layer near the ends of overlap, where the load transfer takes place. Among the many factors affecting the strength of a bonded joint, the stresses in both the adhesive layer and the substrates are probably most crucial to the design of bonded joints [7-10].

Geometric modifications, such as adhesive spew fillet, adherent and adhesive rounding, adherent shaping, e.g., chamfering, adhesive gaps and adhesive grading have significant influence on the reduction of peak stresses, occurring at the ends of the overlap in adhesively bonded joints [6]. Therefore, many approaches have been proposed to reduce the peak stresses [11-13]. Applications of spew fillet and bi-adhesives are examples of these approaches. Performance of bi-adhesives has been studied in single-lap and double-strap joints and measurable increase in the strength of the bi-adhesively-bonded joints is found, when compared with those in which single adhesives were used over the full length of the bondline [14-19]. Despite the material properties, the adhesive joint geometry also led to stress concentration areas in the adhesive/adherent interface, revealed at the edges of the overlap. However, for a given adherent, the lower the stiffness of the adhesive used in the overlap, the lower the stress concentration, leading to potentially higher joint strength. The use of relatively low stiffness adhesives at the ends of the overlap in a bi-adhesive can decrease the stress concentration and, therefore, potentially lead to higher joint strength.

In this study, the application of two adhesives with different stiffness in double-strap joints with embedded patch, subjected to bending moment, was investigated via non-linear Finite Element Analysis (FEA), and the stress distributions in the joints were analyzed. This study is part of an Msc Thesis project. The next step of this study is to perform an experimental work and validate the results with the experimental testing. The same geometry, material, and loading were used in this study, as stated in the Msc Thesis project. 


\section{Non-Linear Finite Element Modelling of The Double-Strap}

\section{Joint (DSJ)}

In the finite element studies, the double-strap (DS) adhesively bonded joint, subjected to bending, using two different single adhesives and a biadhesive was simulated. In this DS joint, patches were embedded into the adherent. Spring steel was used as the patch and Aluminium(AA2024-T3) was used as the adherent bonded with stiff adhesive (FM73 produced by Cytec Fiberite) and softer adhesive (SBT9244 produced by 3M), in this study. The

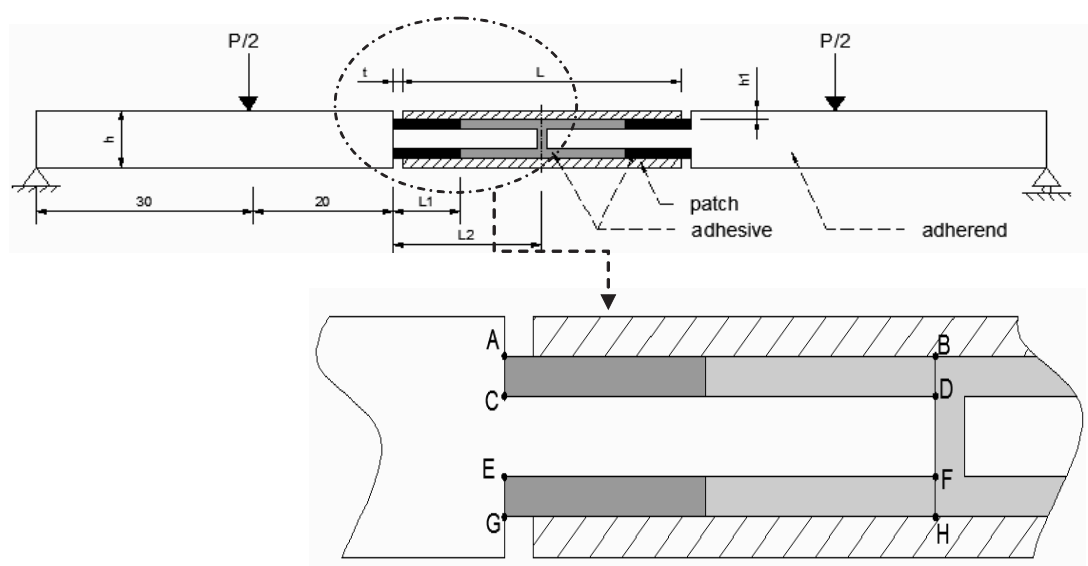

Fig. 1. Double-strap bi-adhesive joint with embedded patch subjected to bending

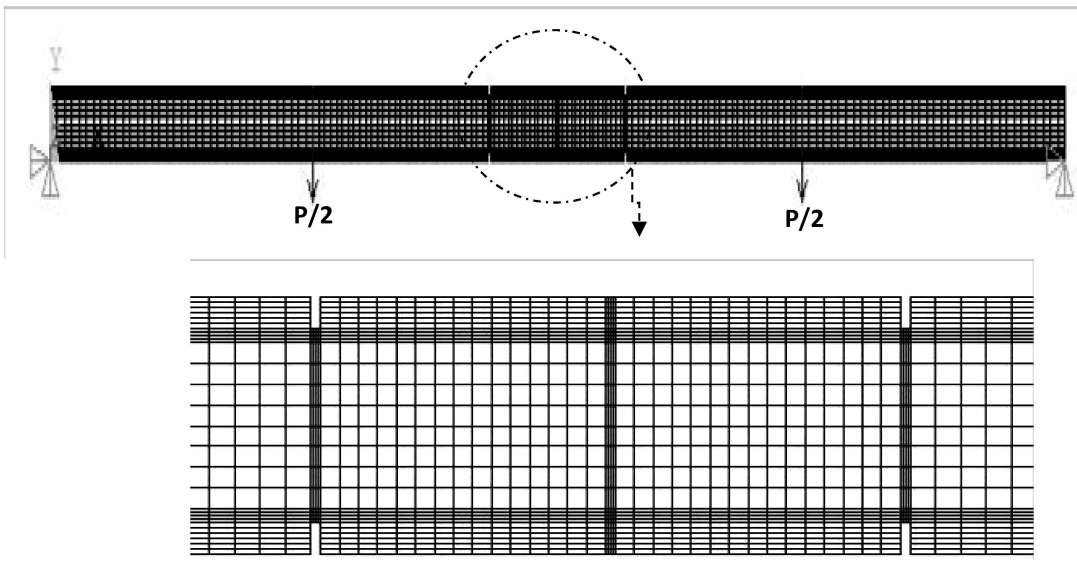

Fig. 2. Mesh details and boundary conditions 
stiff adhesive was located in the middle and the softer adhesive was located at the ends. The joint configuration and the mesh details considered in this study are represented in Figs 1 and 2, respectively.

In the analysis, the material non-linearity based on the uniaxial stressstrain behaviours of adhesives (FM73 and SBT9244) and adherent (AA2024T3) was considered (Fig. 3). The stresses in the patch were below the yield stress of the patch and, therefore, the patch was modelled as a linear-elastic isotropic material. More information on the stress-strain of adhesive and adherent can be found in $[6,14,20]$.

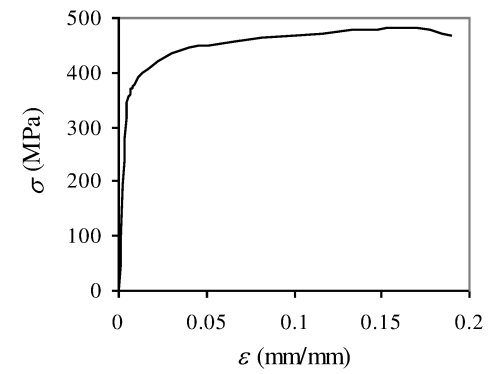

(a)

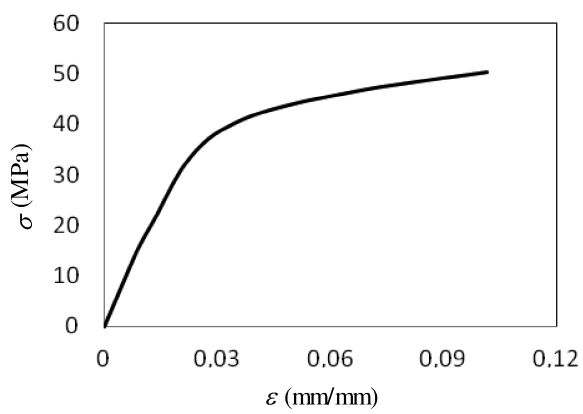

(c)

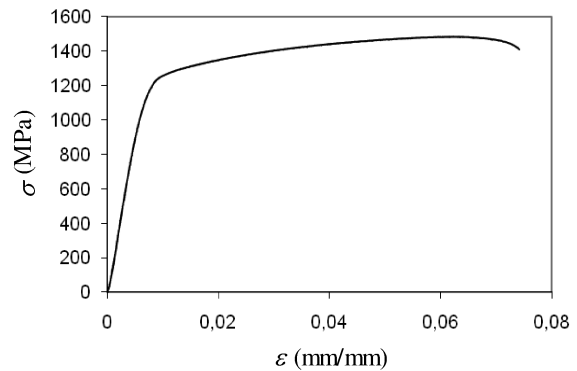

(b)

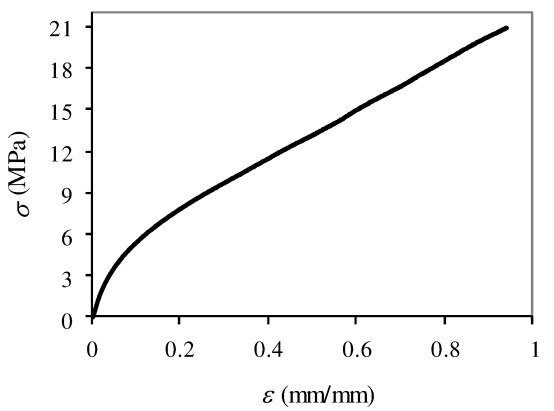

(d)

Fig. 3. Tensile stress-strain curves of adherent, adhesive and patch: (a) AA2024-T3 alloy; (b) Spring steel; (c) FM73 adhesive; (d) SBT9244 adhesive

The effects of different parameters on bonding failure load and joint strength were investigated in this study. These parameters are patch thickness $\left(h_{1}\right)$, total overlap length $(L)$, the length of the embedding part, which is embedded in the main adherent $(h)$ and the depth of the embedding part $(t)$.

The material properties used in the FEM analysis are given in Table 
Table 1. Material properties of the adherent, adhesive and patch used

\begin{tabular}{|c|c|c|c|c|}
\hline & AA2024-T3 Alloy & FM73 Adhesive & SBT9244 Adhesive & Spring Steel \\
\hline$E_{a}(\mathrm{MPa})$ & 71875 & 2093.9 & 82.80 & 220000 \\
$\nu_{e}$ & 0.33 & 0.35 & 0.35 & 0.30 \\
$\sigma_{y}(\mathrm{MPa})$ & 430 & 48 & 4.5 & 1280 \\
$\sigma_{t}(\mathrm{MPa})$ & 482 & 51.05 & 20.97 & 1482 \\
$\varepsilon_{t}$ & 0.16 & 0.11 & 0.94 & 0.06 \\
\hline
\end{tabular}

$E_{a}$ : Young's modulus; $\nu_{e}$ : Poisson's ratio; $\sigma_{y}$ : Yield strength; $\sigma_{t}$ : Ultimate tensile strength, $\varepsilon_{t}$ : Ultimate tensile strain

1. In order to determine the mechanical properties of materials used in this study were prepared as described in Ref. [6]. The geometrical parameters of the joints are shown in Table 2. The thicknesses of adhesive were chosen as $0.25 \mathrm{~mm}$. In addition, the width of adherent was chosen as $25 \mathrm{~mm}$. The other dimensions of the DLJs are shown in Fig. 2. Since effects of thickness and overlap length were examined, the same element dimension was used in all models as often as practicable (see in Table 1 and Fig. 3a). The upper and the lower patch plates have the same dimensions and materials. Three different adherent thickness, patch thickness and overlap length were used. Also, the stress analysis of double-strap joints with embedded patch (DSJEP) under a bending moment was carried out, based on plane strain assumption. The von Mises yield criterion was used to calculate the equivalent stress $\left(\sigma_{e q v}\right)$ and strain $\left(\varepsilon_{\text {eqv }}\right)$ distributions in the adhesive layers and adherents. 2D nonlinear FEM was carried out in the analysis of double-strap adhesively-bonded joints with embedded patch. The ANSYS [21] code version 12.0 and the 8node isoparametric quadrilateral plane element, Plane 82, were employed for the DSJ. The 8-node element is defined with eight nodes having two degrees of freedom at each node, i.e. translation in the nodal $\mathrm{x}$ and $\mathrm{y}$ directions. Mesh distribution area is shown in detail in Fig. 2. Critical regions of stress distributions at the bonding area were divided into smaller elements. The adherent and the adhesive were modelled as different areas and joined with each other using merged nodes. The meshing in adhesive region was performed in a more sensitive manner by dividing it into small pieces $[6,14,22,23]$. In order to perform the stress analysis of the adhesive, elements at adhesive region and at the overlapping planes have been prepared with high density; and elements of outside parts of adhesive regions have been prepared with low density. A refined mesh was used in the contacting surfaces in order to achieve 
Table 2. Geometrical parameters and failure loads, $\mathrm{P}$ of joints

\begin{tabular}{|c|c|c|c|c|c|c|c|}
\hline $\begin{array}{c}\text { Adherend } \\
\text { Thickness } \\
(h) \\
(\mathrm{mm}) \\
\end{array}$ & \begin{tabular}{|c|} 
Patch \\
Thickness \\
$\left(h_{1}\right)$ \\
$(\mathrm{mm})$
\end{tabular} & \begin{tabular}{|c|} 
Overlap \\
Length, \\
$(L)$ \\
$(\mathrm{mm})$ \\
\end{tabular} & $\begin{array}{c}P_{\mathrm{SBT} 9244} \\
(\mathrm{~N})\end{array}$ & $\begin{array}{c}P_{\mathrm{FM} 73} \\
(\mathrm{~N})\end{array}$ & $\begin{array}{c}P_{\mathrm{BI}-\mathrm{ADHES}} \\
(\mathrm{N})\end{array}$ & $\mid \begin{array}{c}L_{1} / L_{2} \\
\text { of BI- } \\
\text { ADHES }\end{array}$ & $\begin{array}{c}\frac{\left(P_{\mathrm{BI}-\mathrm{ADHES}}-P_{\mathrm{FM} 73}\right)}{P_{\mathrm{BI}-\mathrm{ADH}}} \\
(\%)\end{array}$ \\
\hline \multirow{9}{*}{4.8} & \multirow{3}{*}{0.4} & 15 & 1225 & 2050 & 2275 & 0.4 & 10 \\
\hline & & 25 & 1175 & 1950 & 2475 & 0.4 & 21 \\
\hline & & 35 & 1325 & 1900 & 2600 & 0.4 & 27 \\
\hline & \multirow{3}{*}{0.6} & 15 & 1100 & 1800 & 2000 & 0.4 & 10 \\
\hline & & 25 & 1200 & 1575 & 2275 & 0.4 & 31 \\
\hline & & 35 & 1325 & 1575 & 2275 & 0.4 & 31 \\
\hline & \multirow{3}{*}{0.8} & 15 & 1325 & 1425 & 1900 & 0.4 & 25 \\
\hline & & 25 & 1375 & 1300 & 1875 & 0.4 & 31 \\
\hline & & 35 & 1425 & 1300 & 1850 & 0.4 & 30 \\
\hline \multirow{9}{*}{5.6} & \multirow{3}{*}{0.4} & 15 & 1275 & 2550 & 3150 & 0.2 & 19 \\
\hline & & 25 & 1500 & 2650 & 3400 & 0.2 & 22 \\
\hline & & 35 & 1700 & 2700 & 3650 & 0.6 & 26 \\
\hline & \multirow{3}{*}{0.6} & 15 & 1325 & 2475 & 2700 & 0.4 & 8 \\
\hline & & 25 & 1500 & 2550 & 3075 & 0.4 & 17 \\
\hline & & 35 & 1650 & 2400 & 3175 & 0.6 & 25 \\
\hline & \multirow{3}{*}{0.8} & 15 & 1875 & 2150 & 2350 & 0.4 & 9 \\
\hline & & 25 & 1575 & 1850 & 2800 & 0.4 & 34 \\
\hline & & 35 & 1675 & 1875 & 2925 & 0.4 & 36 \\
\hline \multirow{9}{*}{6.4} & \multirow{3}{*}{0.4} & 15 & 1625 & 3300 & 4175 & 0.2 & 21 \\
\hline & & 25 & 1875 & 3475 & 4475 & 0.2 & 22 \\
\hline & & 35 & 2100 & 3525 & 4750 & 0.6 & 26 \\
\hline & \multirow{3}{*}{0.6} & 15 & 1650 & 2825 & 3550 & 0.4 & 20 \\
\hline & & 25 & 1825 & 2900 & 4025 & 0.4 & 28 \\
\hline & & 35 & 2025 & 2925 & 4175 & 0.6 & 30 \\
\hline & \multirow{3}{*}{0.8} & 15 & 2225 & 2450 & 3050 & 0.4 & 20 \\
\hline & & 25 & 1925 & 2500 & 3825 & 0.4 & 35 \\
\hline & & 35 & 2025 & 2500 & 3900 & 0.4 & 36 \\
\hline
\end{tabular}

the convergence and get more contact detection points. All elements in the bondlines of the adhesives were of equal size. This fact was important in order to prevent any problems as the graduation point of the bond-length ratios in the bi-adhesive bondlines varied [24]. The mesh density can affect the strain predictions in the adhesive layer. A smaller element size will generally give a 
higher strain. For this reason, the size of the elements in the mesh was reduced until a stable strain value had been achieved. Consequently, four elements through the adhesive thickness were used in the models, as shown in Fig. 2, and the number of elements was varied for each overlap length. However, the mesh size was kept constant in all models [14].

In the joints with a bi-adhesive, a length $\mathrm{L}_{1}$ from the ends of the overlap was assumed to be bonded with the SBT9244, and the central region was assumed to be bonded with the FM73 adhesive. The nominal bondline thickness considered in all cases was $0.25 \mathrm{~mm}$.

\section{Results and discussion}

\subsection{Effect of bi-adhesive on failure load}

In this study, the half length of the overlap, assumed to be bonded with bi-adhesive, was denoted with $L_{2}$ and the length from the ends of the overlap, assumed to be bonded with SBT9244, was denoted with $L_{1}$. The failure loads of the DSJEP for different adherent and patch thickness, overlap length and $L_{1} / L_{2}$ ratios of bi-adhesive are given in Table 2 and shown in Fig. 4 . In the figures, at $L_{1} / L_{2}=0$, joints are bonded with FM73 adhesive alone and at $L_{1} / L_{2}=1$, joints are bonded with SBT9244 adhesive alone. In order to predict the failure load, the ultimate strain $\left(\varepsilon_{t}\right)$, given in Table 1 , for the adhesives was used. The equivalent stress $\left(\sigma_{\text {eqv }}\right)$ and strain $\left(\varepsilon_{\text {eqv }}\right)$ were calculated using the von Misses yield criterion and it was assumed, that the failure occurred when the equivalent strain $\left(\varepsilon_{\text {eqv }}\right)$ calculated at any point of the adhesive layer reached the ultimate strain $\left(\varepsilon_{t}\right)$ of the adhesive, given in Table 1. A solution in finite element analysis, considering non-linear material behaviour, is reached by dividing the total load in steps to track the equilibrium paths and iterating to a converged solution at each load increment. Hence, a load of $5 \mathrm{~N}$ per $\mathrm{mm}$ width at each load step was applied for all joint types. The remaining load was then applied in the last step [14].

The results in Table 2 show that, except for the failure loads of the two joints with $4.8 \mathrm{~mm}$ adherent and $0.8 \mathrm{~mm}$ patch thicknesses, the failure loads of all the joints, bonded with FM73 alone are greater than the failure loads of all the joints, bonded with SBT9244 alone. The increase ratio in failure loads, due to using bi-adhesive, varies between $9 \%$ and $56 \%$. The maximum predicted failure loads of the joints with bi-adhesive are at about $L_{1} / L_{2}=0.2-0.6$ length ratios.

In Fig. 4(a), the effects of bi-adhesive ratio $\left(L_{1} / L_{2}\right)$ and adherent thickness $\mathrm{h}$ on failure loads of DSJEP for $h_{1}=0.6 \mathrm{~mm}$ thick patch are plotted. When 


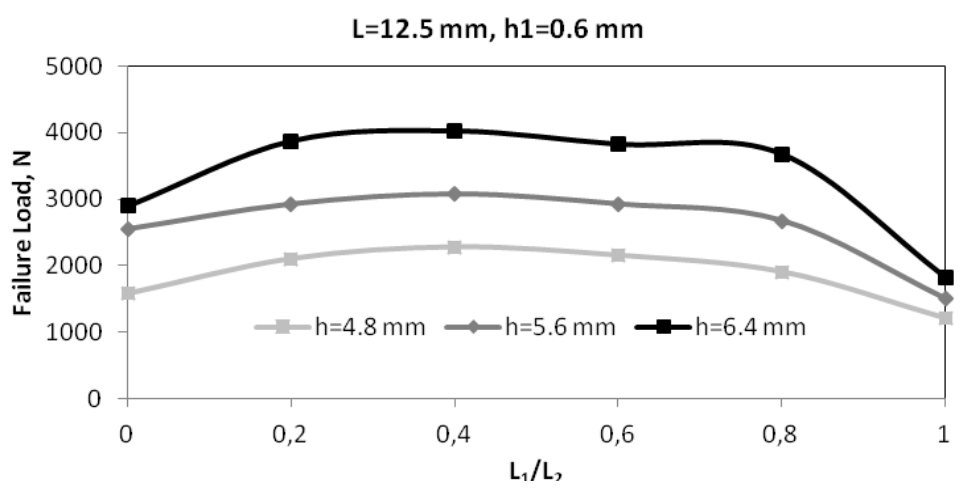

(a)

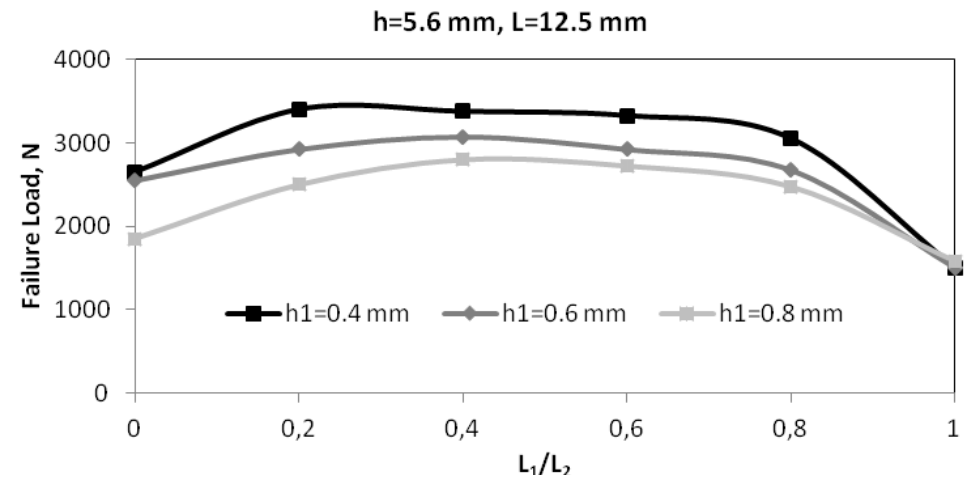

(b)

$\mathrm{h}=5.6 \mathrm{~mm}, \mathrm{~h} 1=0.6 \mathrm{~mm}$

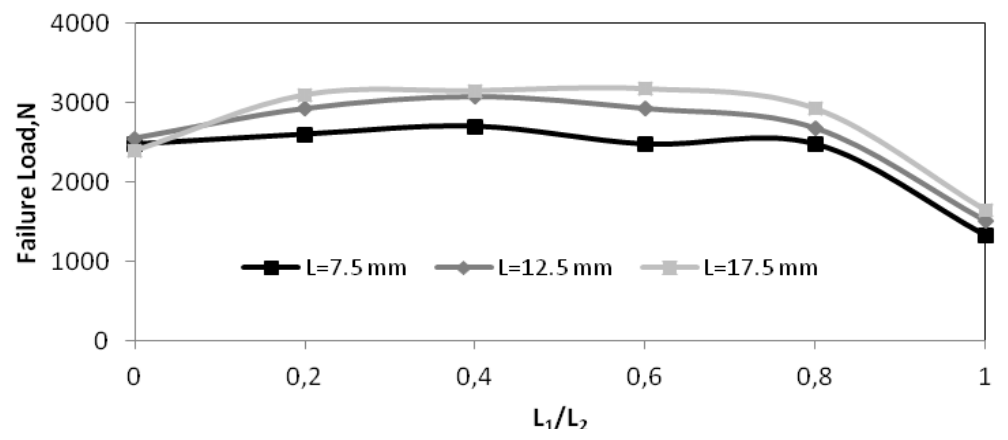

(c)

Fig. 4. Comparison of failure loads for double-strap joints with embedded patch with single- and bi-adhesive. (a) Joints with different adherent thicknesses $\left(L=12.5 \mathrm{~mm}, h_{1}=0.6 \mathrm{~mm}\right)$; (b) Joints with different patch thicknesses ( $L=12.5 \mathrm{~mm}, h=5.6 \mathrm{~mm}) ;(\mathrm{c})$ joints with different overlap lengths $(h=5.6$ $\left.\mathrm{mm}, h_{1}=0.6 \mathrm{~mm}\right)$ 
the figure is examined, it is seen that the effect of the bi-adhesive on the failure loads increases with increase in adherent thickness $\mathrm{h}$. In addition, the difference between failure loads of the joint, bonded with FM73 alone $\left(L_{1} / L_{2}=0\right)$ and failure loads of the joint, bonded with SBT9244 alone $\left(L_{1} / L_{2}=1\right)$ increase with increasing adherent thickness $h$. For three adherent thicknesses, the maximum failure loads of the bi-adhesive occur in $L_{1} / L_{2}=0.4$.

The effects of the bi-adhesive, depending on patch thickness $h_{1}$, on failure loads for $5.6 \mathrm{~mm}$ adherent thickness $\mathrm{h}$ and $25 \mathrm{~mm}$ overlap length $L$ are given in Fig. 4(b). For the joint bonded with SBT9244 alone $\left(L_{1} / \mathrm{L}_{2}=1\right)$, the failure loads of the joints with three patch thickness $h_{1}$ are close to each other. Whereas, the failure loads of the joints bonded with FM73 alone $\left(L_{1} / L_{2}=0\right)$ decreases with increase in the patch thickness. The increase ratio in failure load due to using bi-adhesive reaches $51 \%$, especially in the joint with $0.8 \mathrm{~mm}$ patch thickness $h_{1}$.

The effect of application of bi-adhesive in double-strap joints with embedded patch for different overlap lengths $\mathrm{L}$ is shown in Fig. 4(c). For all three overlap lengths, the failure loads of joints, bonded with FM73 adhesive alone $\left(L_{1} / L_{2}=0\right)$ are almost the same. However, the failure loads of the joints, bonded with SBT9244 alone $\left(L_{1} / L_{2}=1\right)$ increase with increase in the overlap length $\mathrm{L}$. The increase ratio in failure load due to using bi-adhesive increases with increasing the overlap length.

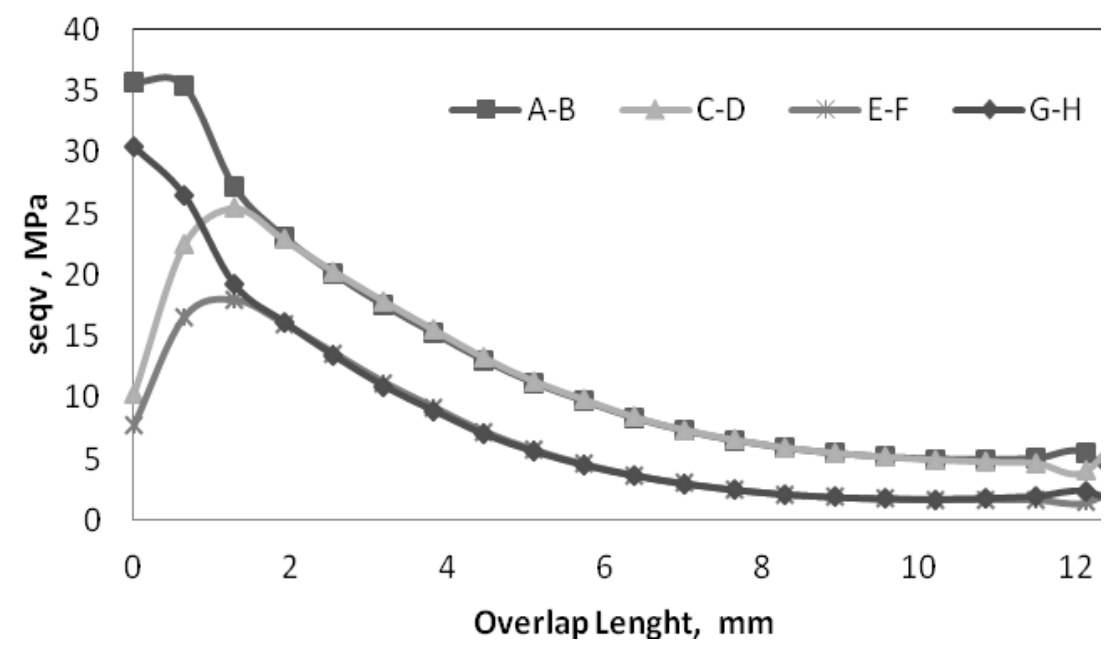

Fig. 5. Equivalent stress distributions along the different bondlines (shown in Fig. 1) on the adhesive side for the DSJ with $5.6 \mathrm{~mm}$ adherent thickness for FM73 adhesive 


\subsection{Effect of bi-adhesive on stress distribution}

To compare the stress distributions of the joints with one adhesive alone and bi-adhesive and to observe the effect of bi-adhesive on stress distributions of double-strap joints with embedded patch, only the joint with $5.6 \mathrm{~mm}$ adherent thickness h, $25 \mathrm{~mm}$ overlap length $\mathrm{L}$ and $0.6 \mathrm{~mm}$ patch thickness $\mathrm{h}$ was analyzed. Here, the joint was subjected to $1000 \mathrm{~N}$ bending load.

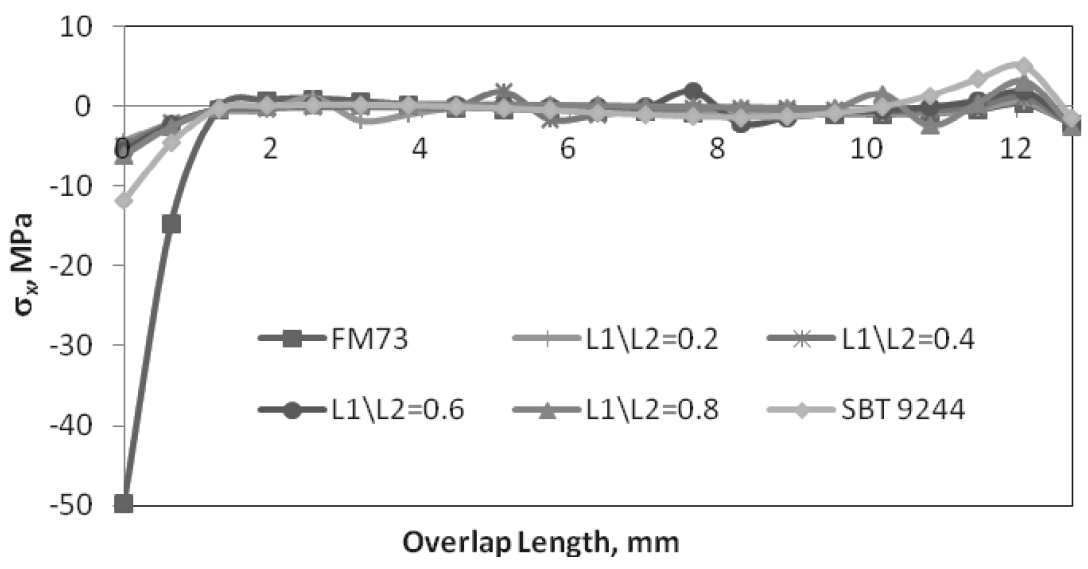

(a)

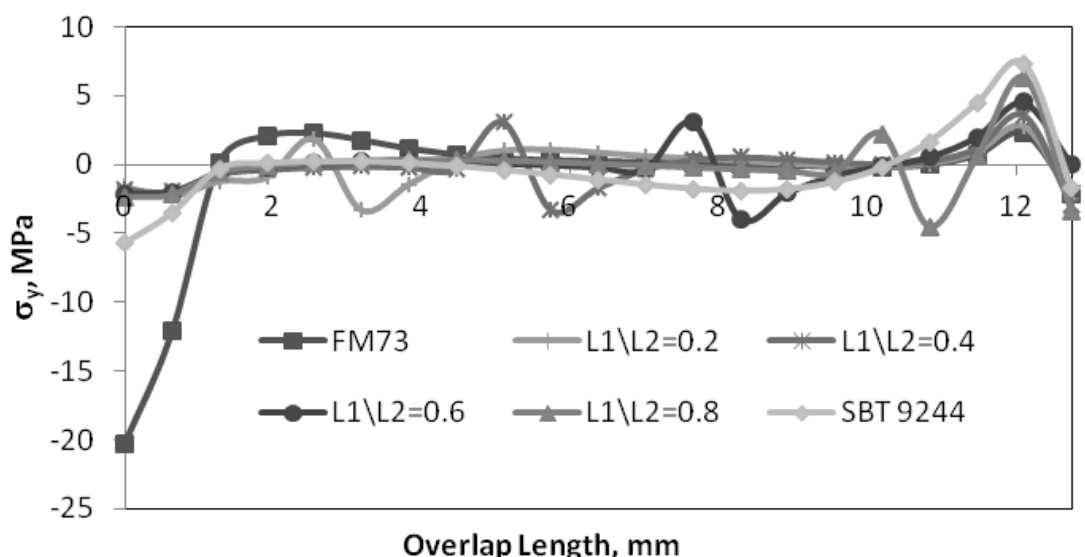

(b)

Fig. 6. longitudinal and peel stress distributions along $\mathrm{A}-\mathrm{B}$ on the adhesive side for different $L_{1} / L_{2}$ ratios with $5.6 \mathrm{~mm}$ thick adherents, $0.6 \mathrm{~mm}$ thick patch and $12.5 \mathrm{~mm}$ overlap length; (a) $\sigma_{x}$, (b) $\sigma_{y}$ 
Four bondlines exist on the adhesive side in the bonding region of the double-strap joint with embedded patch (Fig. 1). The stress distribution in each bondline is different. Therefore, the stresses in the bondlines, for which stresses were maximum and critical were examined, which can be seen in Fig. 5 as the $\mathrm{A}-\mathrm{B}$ bondline. The von Mises equivalent stress at the $\mathrm{A}-\mathrm{B}$ bondline is maximum at point A. So, in this study, all stress distributions plotted are for

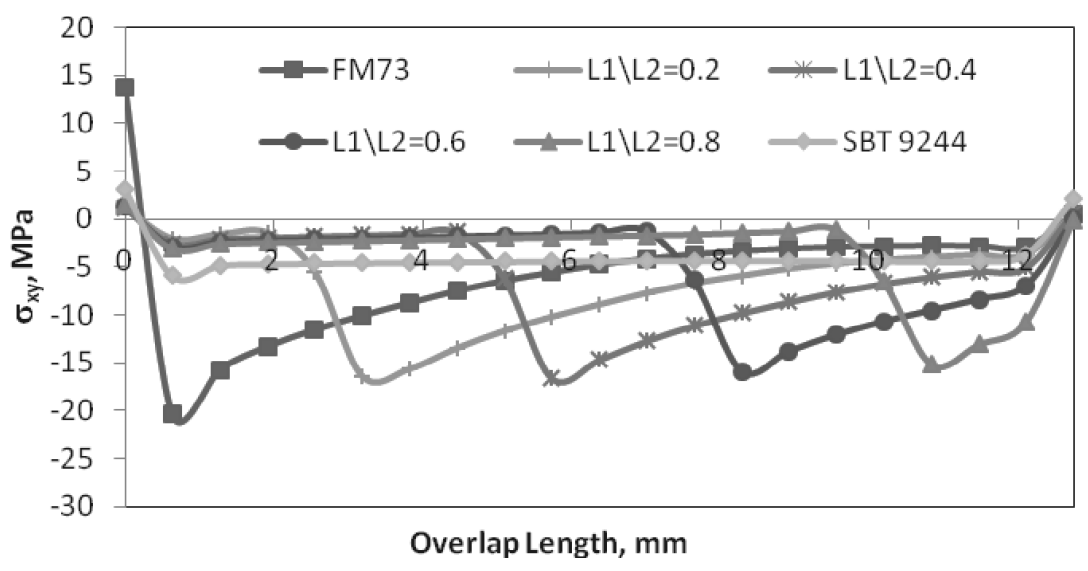

(a)

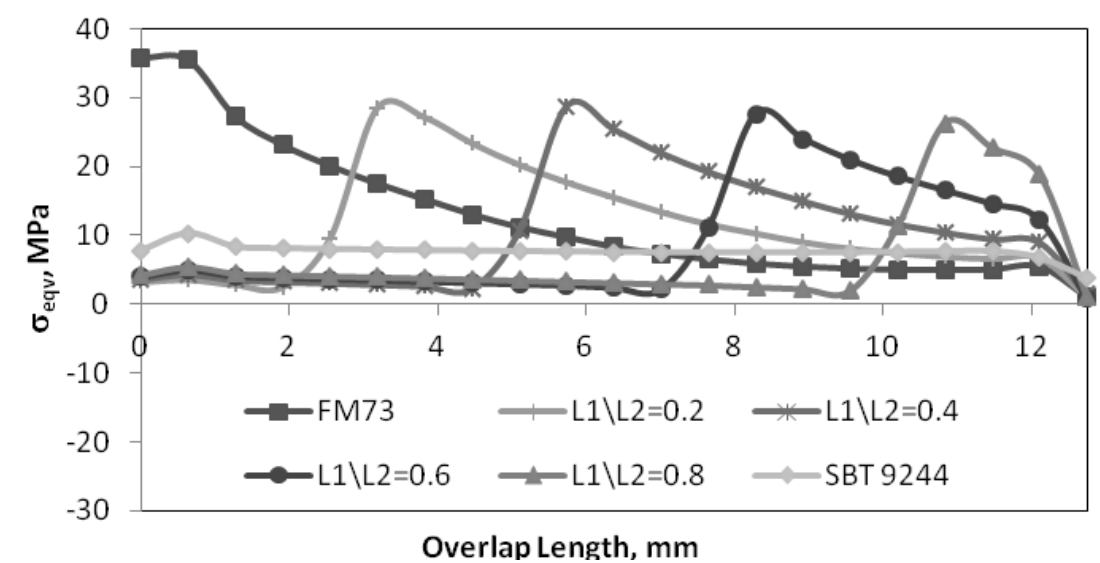

(b)

Fig. 7. Shear and equivalent stress distributions along $\mathrm{A}-\mathrm{B}$ on the adhesive side for different $L_{1} / L_{2}$ ratios with $5.6 \mathrm{~mm}$ thick adherends, $0.6 \mathrm{~mm}$ thick patch and $12.5 \mathrm{~mm}$ overlap length; (a) $\sigma_{x y}$, (b) $\sigma_{\text {eqv }}$ 
the $\mathrm{A}-\mathrm{B}$ bondline.

The longitudinal and peel stress distributions in the joint are given in

Fig. 6. The stresses in the joint with one adhesive alone (FM73 or SBT9244) are larger at point A. Stresses occurred at point A decrease by using the biadhesive. The reason for this is that SBT9244 adhesive is more flexible and load transfer capacity of a flexible adhesive is better due to its high strain to failure, which enables the applied load to be carried by a larger area of the overlap and the joint to be stronger. Also, the flexible properties of SBT9244 contribute to stress relief at the ends of the overlap, reducing the stress concentrations [14]. The stresses are close to zero, when moving away from point A. However, the increase of stress occurs at the intersection of two adhesives $\left(\right.$ at $\left.L_{1} / L_{2}\right)$. This stress increase occurred at the intersection can be seen apparently in Fig. 7. In this figure, the shear and equivalent stress distributions are seen. The stress values are greater than the values of longitudinal and peel stresses.

\section{Conclusion}

In this work, the behaviour of bi-adhesive in double-strap joint with embedded patch is investigated by using finite element method. Our conclusions are as follows:

- The increase ratio in failure loads due to using bi-adhesive varies between $9 \%$ and $56 \%$.

- The maximum predicted failure loads of the joints with bi-adhesive are at about $L_{1} / L_{2}=0.2-0.6$ length ratios.

- The increase ratio in failure load, due to using bi-adhesive, increases with increasing overlap length.

- The effect of the bi-adhesive on failure loads increases with increase in adherent thickness. The reason for the increase in failure load is that load transfer capacity of a flexible adhesive is better than hard adhesive, due to its high strain to failure, which enables the applied load to be carried by a larger area of the overlap and the joint to be stronger. Also, the flexible properties of elastic adhesive (SBT9244) contribute to stress relief at the ends of the overlap, reducing the stress concentrations.

\section{REFERENCES}

[1] Sabrina, F., M. Riadh, Z. XiaO-Ling. Experimental and Finite Element Analysis of a Double Strap Joint between Steel Plates and Normal Modulus CFRP. Composite Structure, 75 (2006), 156-162. 
[2] Lee, H. K., S. H. Pyo, B. R. Kim. On Joint Strengths, Peel Stresses and Failure Modes in Adhesively bonded Double-strap supported Single-lap GFRP Joints. Composite Structure, 8 (2009), 44-54.

[3] Peter, C., R. Francis. Stress Analysis of Double-strap Bonded Joints using a Variational Method. Int. J. Adhesion Adhesives, 21 (2001), 241-247.

[4] Campilho, R. D. S. G., M. F. S. F. De Moura, D. A. Ramantani, J. J. L. Morais, J. J. M. S. Domingues. Tensile Behaviour of Three-dimensional Carbon-epoxy Adhesively Bonded Single- and Double-strap Repairs. Int. J. Adhesion Adhesives, 29 (2009), 678-686.

[5] Jarry, E., R. A. Shenoi. Performance of Butt Strap Joints for Marine Applications. Int. J. Adhesion Adhesives, 26 (2006), 162-176.

[6] Çıtil, Ş, S. Temiz, H. Altun, A. Ozel. Determination of Mechanical Properties of Double-strap Adhesive Joints with an Embedded Patch. Journal Adhesion Sci. Technol., 18 (2011), 2555-2567.

[7] Hart-Smith, L. J. Adhesive-bonded Single-lap Joints, NASA Technical Report CR-112236, TX, Houston, NASA, 1973.

[8] Adams, R. D., J. Comyn, W. C. Wake. Structural Adhesive Joints in Engineering, Amsterdam, Elsevier, 1997.

[9] Adams, R. D., J. A. Harris. The Influence of Local Geometry on the Strength of Adhesive Joints. Int. J. Adhesion Adhesives, 7 (1987), 69-80.

[10] Kinloch, A. J. Adhesion and Adhesives, London, Chapman and Hall, 1993.

[11] Al-Samhan, A., S. M. H. Darwish. Finite Element Modelling of Weldbonded Joints. Journal Mater. Proc. Technol., 142 (2003), 587-598.

[12] Tsai, M. Y., J. Morton. The effect of a Spew Fillet on Adhesive Stress Distributions in Laminated Composite Single-lap Joints. Composite Structures, 32 (1995), 123-131.

[13] Apalak, M. K., R. Davies. Analysis and Design of Adhesively Bonded Corner Joints: Fillet Effect. International Journal Adhesion Adhesives, 14 (1994), 163174.

[14] Temiz, S. Application of Bi-adhesive in Double-strap Joints subjected to Bending Moment. Journal of Adhesion Sci. Technol., 20 (2006), 1547-1560.

[15] Pires, I., L. Quintino, J. F. Durodola, A. Beevers. Performance of Biadhesive Bonded Aluminium Lap Joints. Int. J. Adhesion Adhesives, 23 (2003), $215-223$.

[16] Kumar, S., P. C. Pandey. Behaviour of Bi-adhesive Joints. Journal Adhesion Sci. Technol., 24 (2010), 1251-1281.

[17] DA Silva, L. F. M., C. Q. M. J. Lopes. Joint Strength Optimization by the Mixed-adhesive Technique. Int. J. Adhesion Adhesives, 29 (2009), 509-514.

[18] Das Neves, P. J. C., L. F. M. Da Silva, R. D. Adams. Analysis of Mixed Adhesive Bonded Joints Part II: Parametric Study. Journal of Adhesion Sci. Technol., 23 (2009), 35-61.

[19] Marques, E. A. S., L. F. M. Da Silva. Joint Strength Optimization of Adhesively Bonded Patch. Journal of Adhesion, 84 (2008), 915-934. 
[20] Aydin, M. D., A. Ozel, S. Temiz. Effect of Protrusion at the Ends of Bondline in Single Lap Joints under Tension and Bending. J. Adhesion Sci. Technol., 18 (2004), 1589-1602.

[21] ANSYS. The General Purpose Finite Element Software, TX, Houston, Swanson Analysis Systems, 2012.

[22] Adin, Hamit. The Investigation of the Effect of Angle on the Failure Load and Strength of Scarf Lap Joints. J. Applied Mathematical Modelling, 36 (2012), 2858.

[23] Adin, Hamit, D. M. Emin. Investigation of the Effect of Different Variables on Strength of Adhesive Joints. Mat.-wiss. U. Werkstofftech., 45 (2014), No. 10, 869-878.

[24] Özer, H., Öz Özkan. Three Dimensional Finite Element Analysis of Biadhesively Bonded Double Lap Joint. International Journal of Adhesion \& Adhesives, 37 (2012), 50-55. 